\title{
Vocalization as an objective measure of shock-elicited social aggression in rats*
}

\author{
DONALD H. THOR, WILLIAM B. GHISELLI, and LLOYD D. WILSON \\ E. R. Johnstone Training and Research Center, Bordertown, New Jersey 08505
}

\begin{abstract}
Intense vocalizations emitted by pairs of shocked rats were compared when physically separated by a transparent partition and when free to engage in social aggression. Greater vocalization occurred in the free-access condition and was positively correlated with visually observed attack scores in pairs that had prior experience with shock. A second experiment determined the influence of repeated fighting exposures upon the correlation between observed attack and vocalization. High positive correlations were obtained after initial sessions within a broad range of intermediate fighting. At high and low extremes of fighting, correlations were nonsignificant. The results are discussed with reference to restriction imposed upon variation of attack scores based upon standard criteria of observation.
\end{abstract}

Aggressive behavior of rodents in experimental situations is normally measured by visual observation on the basis of some type of scoring system. Although inter-O reliability is usually high, different investigators employ a variety of scoring techniques. Criteria range from the occurrence of very specific individual behaviors such as biting (Azrin, Rubin, \& Hutchinson, 1968) or posturing (Kimbrell, 1969) to systems combining a few (Eichelman, 1971) or many (Krsiak \& Steinberg, 1969) behaviors. Problems inherent in such criteria differences have been discussed elsewhere (Kimbrell, 1968). It is apparent that an automated measurement incorporating a technique and criteria reproducible across laboratories would be of general value in the analysis of variables related to aggression.

A series of recent experiments (Thor, 1971; Thor \& Hoats, 1970; Thor, Hoats, \& Thor, 1970) has introduced a method of recording vocalizations accompanying fighting as an index of aggressive behavior in grouped rats. The technique was adopted on the basis of observed vocal behavior accompanying the fighting occurring during opiate withdrawal and the need for continuous automated surveillance of group fighting over the extended interval of withdrawal. This form of monitoring was particularly useful, since the recordings allowed reliable distinctions of (a) the onset and offset of fighting in reference to terminal drug dosage, and (b) the experimental manipulations which modified the withdrawal-induced fighting. Lal, O'Brien, and Puri (1971) used an improved method for a comparable psychopharmacological investigation, and Morgret (1972) and Morgret and Dengerink (1972) designed a system for recording vocalizations during fighting in mice. Modified recording systems have also been described by Crabtree and Moyer (1972) and by Davis. Perrott, and Hubbard (1972).

The present investigation attempted a more detailed analysis of vocalization as a measure of agonistic behavior. Footshock was selected as the method of

\footnotetext{
*Supported by Research Grant MH 21577-01 from NINH.
}

eliciting attack, since it is the most common method for investigating the aggressive behavior of rodents.

\section{EXPERIMENT I}

Rats shocked individually emit vocalizations that change with shock parameters and shock experience (Badia \& Culbertson, 1971; Badia, Defran, \& Lewis, 1968). The initial experiment attempted to establish the presumed difference in vocalizations when pairs of rats are allowed to fight as compared to pairs shocked under identical parameters, but physically prevented from fighting. Secondly, it was of interest to determine whether vocalizations would covary with fighting behavior.

\section{Method}

\section{Subjects}

The Ss were 64 socially reared (100-day-old) male Long-Evans rats. All Ss had experienced one prior session of shock-elicited fighting.

\section{Apparatus}

The fighting chamber, enclosed within an Industrial Acoustics Model AC-1 acoustic chamber equipped with a viewing portal, was a $20 \times 20 \times 20 \mathrm{~cm}$ box with walls of wood and Plexiglas. The grid floor consisted of $1 / 4$-in. brass rods spaced $5 / 8$ in. apart. A removable Plexiglas divider could be inserted to partition the fighting chamber equally. Constant-current shock was delivered from a Lafayette A-615A shock source through a Lafayette Model 5820 neon grid scrambler. Vocalizations were sensed by a crystal microphone located on one wall of the fighting chamber. To exclude extraneous noise, the microphone signal was initially passed through a $3-\mathrm{kHz}$ narrow bandpass filter to an Eicocraft $\mathrm{EC}-1700$ voice-activated relay. Within the fight chamber, a $3-\mathrm{kHz}$ tone of $95-105 \mathrm{~dB}$ (as measured with a Brüel \& Kjaer Mlodel 2203 sound level meter) from a 4 -in. PM speaker located 6 in. from the microphone was sufficient to activate the relay.

\section{Procedure}

The $64 \mathrm{Ss}$ were assigned to 32 pairs on the basis of matching weight and housed + per cage under constant illumination for 
Table 1

Correlation Coefficients for Vocalizations and Visually Observed Attack

\begin{tabular}{llccc}
\hline & & \multicolumn{3}{c}{ Fighting Session } \\
\cline { 3 - 5 } & \multicolumn{1}{c}{$\begin{array}{c}\text { Mecalization } \\
\text { Measure }\end{array}$} & 1 & 2 & Combined \\
\hline A & Fighting & -.40 & $.75^{* *}$ & $.48^{*}$ \\
B & Partitioned & -.25 & .44 & -.32 \\
C & Increment (A-B) & .10 & $.80 \dagger$ & $.56^{* *}$ \\
\hline & $* p<.01$ & $* * p<.001$ & $t p<.0001$
\end{tabular}

the duration of the experiment. Food and water were provided ad lib. Each pair was run in two sessions. During one session, the transparent partition was in place and fighting was prevented, and during the other session. the partition was absent and fighting could occur. A session consisted of $500.5-\sec 2.0-\mathrm{mA}$ shocks delivered at 7.5-sec intervals. The order of sessions was counterbalanced. and the sessions were separated by an interval of 3 days. The pairs remained the same throughout the experiment but were housed in separate group cages.

An attack was defined after Eichelman (1971); briefly, a visually observed attack was said to have occurred when a directed movement by a rat toward the opponent resulted in contact. followed by at least one of the following behaviors: biting, sparring, upright attack posturing, or submissive posturing. This definition was used, in full knowledge that alternatives exist, with the intent of encompassing sufficient behaviors to qualitatively describe social aggression in this species (cf. Grant \& Mackintosh, 1963; Utrich \& Azrin, 1962). Two Os recorded attacks independently during fighting, with the stipulation that no more than one attack be scored following each shock. Attacks and vocalizations were registered on separate banks of a printing counter. Fighting was expressed as the percentage of shocks effective in eliciting an attack. For purposes of analysis, a logarithmic transformation was made on the vocalization data as the result of its positively skewed distribution.

\section{Results}

Fighting occurred in all pairs, ranging from $16 \%$ to 93\%. Pairs tested without the partition on Session 2 tended to fight more $(69.0 \%)$ than those tested without the partition on Session $1(56.4 \%)$, although this difference did not approach significance $(t=1.34$, $\mathrm{df}=$ 31). Vocalizations also occurred in all pairs, both when fighting and when separated. There was significantly more vocalization $(F=27.53, p<.0005)$ when paired animals fought $(M=203.8)$ than when they were shocked but prevented from fighting by the transparent partition $(M=149.8)$. As with the fighting measure, the apparent tendency for vocalizations to increase on Session 2, when engaged in fighting, was not significant $(F<1.0)$, nor did sessions interact with conditions $(\mathrm{F}<1.0)$.

Correlation coefficients were computed between the attack data, derived when the partition was removed, and each of the following: (A) vocalizations occurring concurrently with fighting, (B) vocalizations occurring in the same pair but when separated by the partition, and (C) the change in vocalization of a pair when prevented from fighting and when allowed to fight (i.e., A-B). Table 1 presents the correlations for individual fighting sessions $(N=16)$ and when Sessions 1 and 2 were pooled $(N=32)$ within each condition. Significant positive coefficients were obtained for the pooled data between fighting and concomitant vocalizations and for increments in vocalizations when Ss were allowed to fight. It is apparent from the data for individual sessions (Table 1) that these relationships were only present for pairs that had been separated on Session 1 and had fought on Session 2.

\section{Discussion}

The two measures of vocalization directly involved with fighting, concurrent vocalization and the increment measure, demonstrated highly significant and positive correlations with fighting on Session 2. The appearance of strong correlations only on Session 2 implies that they may have been the result of the experience of being shocked while prevented from fighting or simply the greater shock experience of Ss fighting on Session 2. Individual rat vocalizations to shock (Badia et al, 1968) and fighting behavior of paired animals in response to shock (Creer \& Powell, 1971a) generally show increments over the initial exposures to shock. The increment in both vocalization and fight scores of fighting pairs between Session 1 and Session 2, while not significant, lend credence to prior shock experience as underlying the apparent development of a positive relationship between fighting and vocalizations. During initial experience with shock, vocalization may occur primarily as the result of shock and minimally because of fighting.

\section{EXPERIMENT II}

The primary objective of Experiment II was to determine if the relationship between fighting and vocalization develops as a function of testing experience. The well-known "sessions effect" in shock-induced fighting is that of an increase in attack frequency with increases in aggressive exposures (Creer \& Powell, 1971a; Vernon \& Ulrich, 1966). Some investigators incorporate numerous preliminary sessions to achieve high and stable levels of attack (Azrin, Ulrich, Hutchinson, \& Norman, 1964; Powell, Francis, Braman, \& Schneiderman, 1969). However, in some cases, manipulations that produce initial differences in fighting behavior appear to lose their effectiveness with repeated sessions (Creer \& Powell, 1971b; Payne, Anderson, \& Murcurio, 1970).

On the basis of original shock-induced fighting, a group of high-fighting pairs and a group of low-fighting pairs were formed. Each pair in each group then received repeated exposures to shock in the fighting chamber. Correlations of attack and vocalization measures over sessions were anticipated to increase as fighting stabilized. High- and low-fighting pairs were compared to reveal the interactive effect of fighting level and experience with shock-elicited fighting. Since fighting 
can be modified by altering sensory input (Bugbee \& Eichelman, 1972), it is conceivable that distinctive auditory cues from intense vocalization may serve to modify fighting behavior of paired rats under stress.

\section{Method}

\section{Subjects}

Twenty additional pairs of rats were selected from the pool used to provide Ss for Experiment I. Ten pairs were selected on the basis of high-fighting (HF) scores and 10 pairs on the basis of low-fighting (LF) scores. The two resulting groups differed significantly $(\mathrm{p}<.001)$ on percentage of attacks $(t=30.0)$ and amount of vocalization $(t=4.2)$ emitted during fighting.

\section{Apparatus}

The apparatus was that used in Experiment I.

\section{Procedure}

Each pair was given eight consecutive daily fighting sessions, as in Experiment I. Members of each pair were housed in separate cages.

\section{Results}

The attack rate of the LF group increased from $1.2 \%$ on Session 1 to $68.5 \%$ on Session 8 . In contrast, the HF group increased from $80.5 \%$ attacks on Session 1 to $90.1 \%$ attacks on Session 8. Figure 1 presents means and standard errors of attack data for both groups. Although

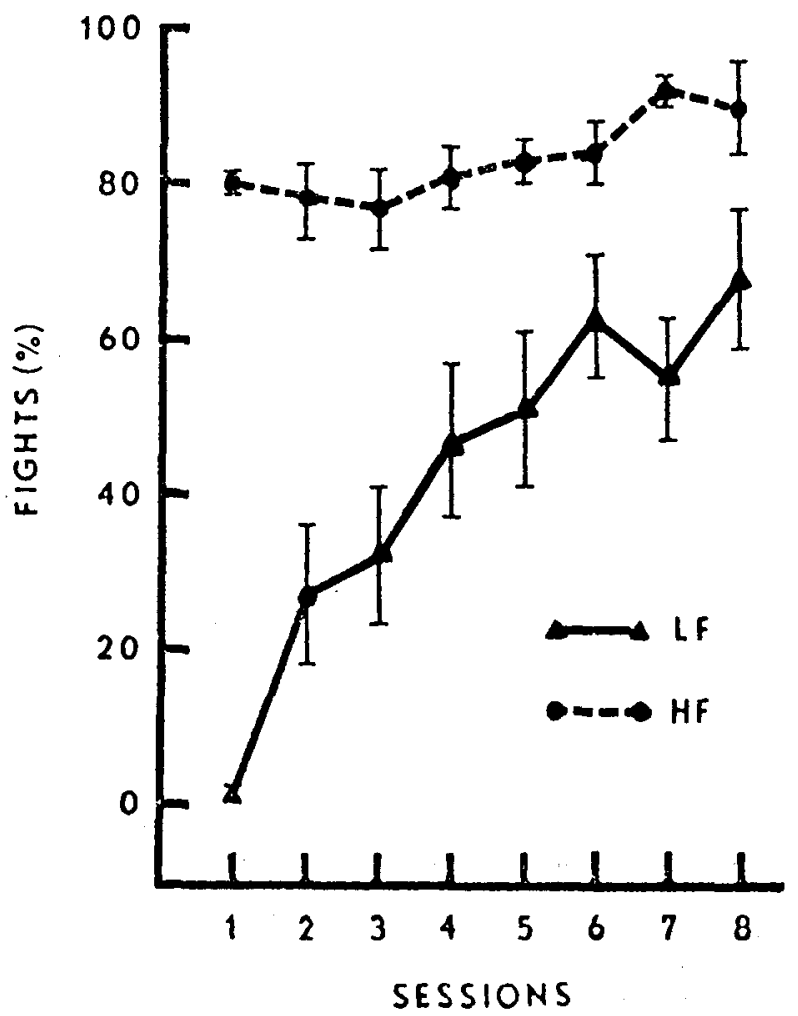

Fig. 1. Mean percentage of $\mathrm{O}$-scored fighting for original lowand high-fighting pairs of rats by sessions. Vertical bars indicate standard error of the mean.

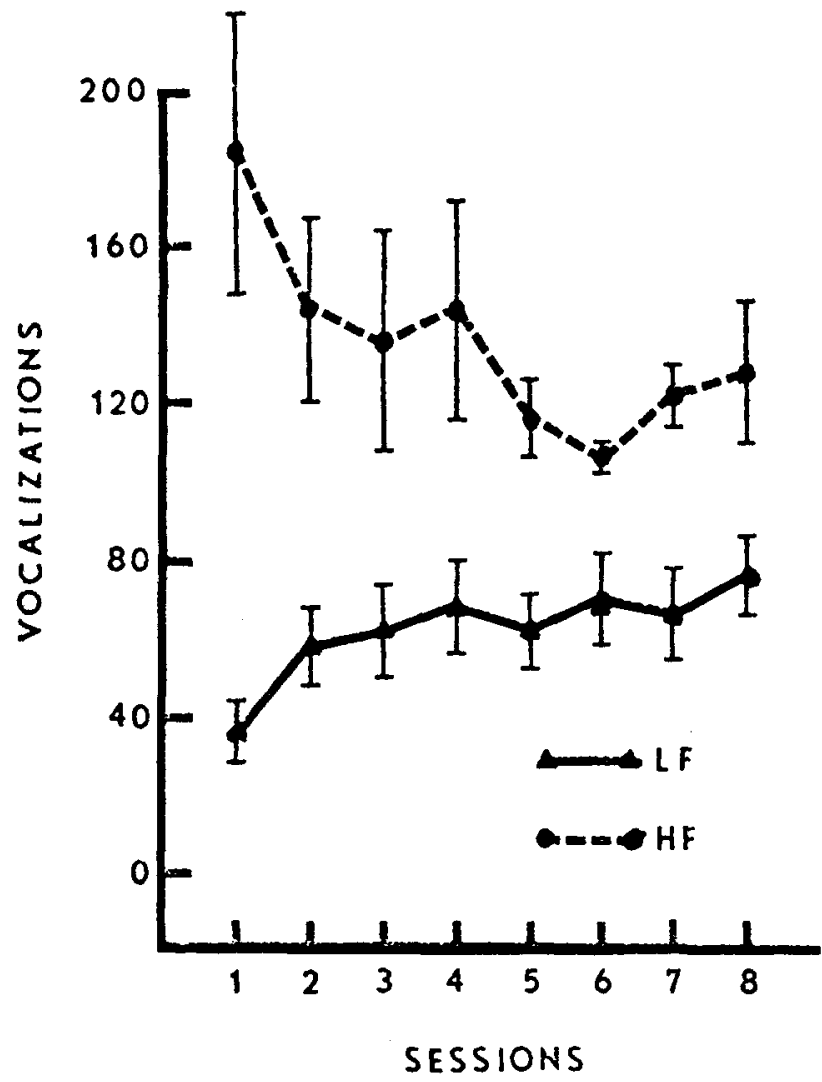

Fig. 2. Mean vocalizations recorded for original low- and high-fighting pairs of rats by sessions. Vertical bars indicate standard error of the mean.

the convergence of group means over sessions is readily apparent, the LF group was still fighting significantly less on Session $8(t=2.38, p<.05)$. Vocalization means over sessions also tended to converge (Fig. 2), with the HF group decreasing and the LF group increasing. Again, however, at Session 8 the LF group vocalized less than the HF group $(\mathrm{t}=2.45, \mathrm{p}<.05)$.

Since the attack scores were negatively skewed, a square root transformation was applied. A logarithmic transformation was performed on vocalization data, as in Experiment I. Correlation coefficients between the transformed scores for each group on each session are presented in Table 2. Distinct differences in the coefficients between fighting and vocalization were obtained between the HF and LF groups: significant positive correlations occurring for the LF and predominantly nonsignificant correlations for the HF group. The magnitude of the correlation increased as a function of fighting experience for the LF group, but changed very little for the HF group. On Sessions 1-3. the coefficients of the HF and LF groups did not differ significantly; on Sessions 4-8. however, the LF coefficients were significantly higher than those for the HF group $(p<.001, .05, .01, .001$, and .001. respectively). By the final session, $96 \%$ of the variance in the attack measure of the LF group was accounted for by variation in the vocalization measure. Residual variation was sufficiently low to be attributed to inter-O differences. 
Table 2

Pearson Product-Moment Correlation Coefficients Between Transformed Attack and Vocalization Measures

\begin{tabular}{ccc}
\hline & \multicolumn{2}{c}{ Fight Group } \\
\cline { 2 - 3 } Session & High & Low \\
\hline 1 & .19 & -.26 \\
2 & $.63^{*}$ & $.64^{*}$ \\
3 & .43 & $.87^{* *}$ \\
4 & .23 & $.99 \dagger$ \\
5 & .46 & $.91 \dagger$ \\
6 & .25 & $.94 \dagger$ \\
7 & .24 & $.97 \dagger$ \\
8 & .23 & $.98 \dagger$ \\
\hline${ }^{*} p<.05$ & $* * p<.001$ & $t_{p}<.0001$
\end{tabular}

Pearson coefficients were also computed for inter- 0 attack scores of each pair of Ss over all sessions. Inter-O agreement was high for both HF and LF groups. However, the LF group had a higher $(\mathrm{t}=2.9, \mathrm{p}<.01)$ mean inter $\cdot O$ correlation $(\overline{\mathrm{X}}=.98, \mathrm{SD}=.04)$ than did the HF group $(\overline{\mathrm{X}}=.85, \mathrm{SD}=.14)$, but the HF group was also more variable in $\mathrm{O}$ reliability $(\mathrm{F}=14.8, \mathrm{p}<.001)$. Lower reliability in the $O$ measurement of fighting in the HF group parallels the lower correlation coefficients between fighting and vocalization also found in this group (Table 2). Conversely, the LF group showed greater reliability of the $O$ measurement of attack in addition to the significantly greater correlation between the two measures of fighting.

\section{Discussion}

The present data support the findings of Experiment I. Evidently a strong positive correlation exists between rater-observed fighting scores and objectively recorded vocalizations when attack scores range over a moderate level of attack $(28 \%-69 \%)$, as in the LF group. In contrast, the HF group had consistently high attack scores (80\%-90\%), which did not correlate significantly with vocalization. The correlation for HF pairs may be spuriously low due to a restriction in the range of one or both measures. High correlations between the dependent measures appear when the attack measure has no restriction upon its range of variation; i.e., standard errors of the attack scores in Fig. 1 are positively correlated with the coefficients of the LF ( $r=.95)$ and HF $(r=.62)$ groups in Table 2 . A restriction in attack variance could be the result of the ceiling produced by its operational definition or by fighting and vocalizations having reached an asymptote.

\section{GENERAL DISCUSSION}

High-intensity vocalizations are highly correlated with visually observed attack when fighting is within a moderate range of magnitude. Although this observation may be restricted, to specific aspects of the emitted signal as measured in the present case, it is entirely conceivable that additional combinations of signal parameters may prove more applicable for specific analyses of rodent aggression.

Shock normally elicits vocalization when applied to individual Ss, and prior shock experience alters subsequent aggression (Payne et al, 1970). Consequently, the relationship of vocalization to fighting may be more parsimoniously determined by other methods of stimulating fighting. For example, Morgret and Dengerink (1972) have found correlations ranging from .48 to .98 (accounting for approximately half the variance) between vocalization and spontaneous fights when previously isolated male mice were placed in the same cage. These investigators have also elaborated the advantages of automated recording of vocalization as a measure of aggressive behavior; they conclude that the greatest advantage may lie in applications for objective and continuous measurement during extended time intervals.

Refined observational techniques, as well as additional methods of eliciting aggression, will further serve to delineate advantages and disadvantages of vocalization as an objective indicant of aggressive response. Of greater interest will be the subsequent specification of vocalization measures to attack or defense roles assumed by the individual organism and the import of auditory stimulation in aggressive responding of rodents.

\section{REFERENCES}

Azrin, N. H., Rubin, H. B., \& Hutchinson, R. R. Biting attack by rats in response to aversive shock. Journal of the Experimental Analysis of Behavior, 1968, 11, 633-639.

Azrin, N. H., Ulrich, R. E., Hutchinson, R. R., \& Norman, D. G. Effect of shock duration on shock-induced fighting. Journal of the Experimental Analysis of Behavior, 1964, 7, 9-11.

Badia, P., \& Culbertson, S. Stimulus induced attenuation of rat vocalizations to tail shock: Shock intensity effects. Psychonomic Science, 1971, 22, 267-268.

Badia, P., Defran, R. H., \& Lewis, P. CS-US interval and suppression of unconditioned vocalization to shock: Associative or non-associative. Psychonomic Science, 1968, 13, 269-270.

Bugbee, N. M., \& Eichelman, B. S. Sensory alterations and aggressive behavior in the rat. Physiology \& Behavior, 1972, 8, 981-985.

Crabtree, J. M., \& Moyer, K. E. An analysis of measures of aggressive behavior in the rat induced by shock and morphine withdrawal. Paper presented at the meetings of the Midwestern Psychological Association, Cleveland, May 1972.

Creer, T. L., \& Powell, D. A. Effects of age and housing conditions on shock-induced aggression. Psychonomic Science, 1971a, 22, 259-261.

Creer, T. L., \& Powell, D. A. Effect of repeated shock presentations and different stimulus intensities on shock-induced aggression. Psychonomic Science, 1971b, 24, 133-134.

Davis, H., Perrott, D., \& Hubbard, J. An automated apparatus for recording shock elicited vocalization in the rat. Psychological Record, 1972, 22, 71-74.

Eichelman, B. S. Effects of subcortical lesions on shock induced aggression. Journal of Comparative \& Physiological Psychology, 1971, 74, 331-339. 
Grant. I. C.. \& Mackintosh. J. H. A comparison of the social postures of some common laboratory rodents. Behaviour, 1963.21, 246.259.

Kimbrell. G. M. "Fighting response": A definitional problem. Psychological Record, 1968. 18.639-640.

Kimbrell. G. M. Relationship of the upright agonistic posture in the foot shock situation to dominance-submission in male C57BL/6 mice. Psychonomic Science, 1969, 16, 167-168.

Krsiak. M., \& Steinberg, H. Psychopharmacological aspects of aggression: $A$ review of the literature and some new experiments. Journal of Psychosomatic Research, 1969, 13. 243-252.

Lal, H., O'Brien, J.. \& Puri, S. K. Morphine withdrawal aggression: Sensitization by amphetamines. Psychopharmacologia (Berlin), 1971, 22, 217-223.

Morgret, M. K. An apparatus for detection and counting of mouse squeals. Behavior Research Methods \& Instrumentation, 1972, 4, 21-23.

Morgret, M. K., \& Dengerink, H. A. The squeal as an indicator of aggression in mice. Behavior Research Methods \& Instrumentation, 1972, 4, 138-140.

Payne, R., Anderson, D. C., \& Murcurio, J. Preshock-produced alterations in pain-elicited fighting. Journal of Comparative \&
Physiological Psychology, 1970. 71. 258-266.

Powell, D. A., Francis, J., Braman, M. J., \& Schneiderman, N. Frequency of attack in shock-elicited aggression as a function of the performance of individual rats. Journal of the Experimental Analysis of Behavior, 1969, 12, 817-823.

Thor, D. H. Amphetamine induced fighting during morphine withdrawal. Journal of General Psychology, 1971, 84, 245-250.

Thor, D. H., \& Hoats, D. L. Morphine-amphetamine-induced fighting and interim socialization. Psychonomic Science, $1970,20,156-158$.

Thor, D. H., Hoats, D. L., \& Thor, C. J. Morphine induced fighting and prior social experience. Psychonomic Science, $1970,18,137-139$

Ulrich, R. E., \& Azrin, N. H. Reflexive fighting in response to aversive stimulation. Journal of the Experimental Analysis of Behavior, 1962, 5, 511.520

Vernon, W.. \& Ulrich, R. E. Classical conditioning of pain-elicited aggression. Science. 1966, 152, 668-669.

(Received for publication April 9, 1973; revision received July 9,1973 .) 